\title{
Ali celovita sanacija vpliva na spremembo cen stanovanj? Študija primera v predelu Mongkok v Hongkongu
}

Propadanje mestnih predelov je neizogibna posledica rasti večine mest, tudi Hongkonga. Veliko starih stavb v Hongkongu je v slabem stanju in v mestu je nujno treba začeti reševati problem propadanja. Sanacijo propadajočih stavb so dolgo razumeli kot učinkovito rešitev tega urbanističnega problema, vendar pa je $\mathrm{v}$ literaturi navedeno, da lahko ta vodi v gentrifikacijo sosesk, saj lahko povzroči povečanje cen nepremičnin in najemnin v bližini prenovljenih območij. Kljub temu obstaja le malo empiričnih raziskav o tem, kako celovita sanacija vpliva na vrednost stanovanj v soseski. $V$ tej študiji se preučujejo vplivi sanacije ulic Argyle in Šanghaj, torej projekta, ki je potekal pod okriljem urada za urbano prenovo, in na transakcijske cene stanovanj v bližini. V študiji je uporabljen niz panelnih podatkov, avtor pa preučuje tudi spre- membe $\mathrm{v}$ razponu cen glede na lokacijo (ang. spatial price gradient) pred začetkom projekta sanacije in po tem, ko se je ta končal. Ugotovitve kažejo, da je bližina projektne lokacije pomembno vplivala na cene stanovanj pred začetkom projekta, in sicer pozitivno. Potem ko se je projekt končal, ni bilo vidnih sprememb v cenah stanovanj glede na lokacijo. Ti izsledki potrjujejo ugotovitve predhodne raziskave, in sicer dejstvo, da cene stanovanj niso odvisne od sprememb v okoljski kakovosti, ki je posledica celovite sanacije.

Ključne besede: cena stanovanj, celovita sanacija, gentrifikacija, zunanji učinki, hedonska analiza cen, Hongkong 


\section{Uvod}

Ko mesto raste, je popolnoma običajno, da njegovo mestno okolje propada (Khaki idr., 1999). Zadnjih nekaj desetletij prebivalci Hongkonga uživajo sadove hitre gospodarske rasti, obenem pa se spopadajo z dolgotrajnim problemom propadanja mestnih predelov. Približno četrtina 39.000 zasebnih stavb v mestu je na različnih stopnjah propadanja (urad za stanovanja, načrtovanje in zemljišča, 2005). Val propadanja stavb prej ali slej povzroči, da začnejo propadati tudi celotni mestni predeli, kar kazi podobo mnogih dobro razvitih mest (De Kleijn, 1986; Andersen, 1995). Zaradi negativnih zunanjih posledic propadanja stavb (na primer ogroženo javno zdravje in varnost) je za reševanje problema potrebna urbana prenova ali sanacija. Gre za proces, pri katerem se stavbe, ki propadajo ali so z vidika funkcionalnosti zastarele, izboljšajo $\mathrm{z}$ različnimi metodami, kot so celovita sanacija, obnova in modernizacija (Dumouchel, 1975). Sanacija je med različnimi pristopi $k$ urbani prenovi mogoče še vedno najpogostejša. Kljub temu pa so pobude za sanacijo propadajočih stavb v Hongkongu, ki jih je sprožil urad za urbano prenovo (ang. Urban Renewal Authority, v nadaljevanju: URA), pred kratkim naletele na nasprotovanje. Ker se velik del sredstev porabi za izplačilo odškodnin prizadetim stanovalcem v procesu združevanja zemljišč, je ena mnogih pritožb ta, da hongkonška vlada javnega denarja ne bi smela porabljati za podporo projektov sanacije, ki jih vodi URA. Poleg tega se nekateri pritožujejo, da se morajo zaradi urbane sanacije razseliti prvotni stanovalci in da ta negativno vpliva na lokalno gospodarstvo. Da bi te sporne projekte upravičili, morajo javni organi običajno opraviti analizo stroškov in koristi (Litchfield, 1966, 1967; Messner, 1967; Rothenberg, 1967).

Čeprav so stroški in koristi projekta sanacije lahko nedenarni (na primer uničenje socialne mreže in izboljšana kakovost življenja stanovalcev), se čisti denarni zaslužki uporabljajo v različne namene, kot je na primer merjenje vladne učinkovitosti v projektu urbane sanacije (Broadway, 1974). Pri ocenjevanju koristi moramo upoštevati, kako projekt izkorišča razvojni potencial na območju sanacije ter ustvarja posredne in neposredne priložnosti za nova delovna mesta, obenem pa ne smemo prezreti njegovih morebitnih učinkov prelivanja. Že več znanstvenikov (na primer Rosenthal in Helsley, 1994, ter Baleiras idr., 2004) je ugotavljalo, da lahko obsežni projekti izboljšav ali sanacij zvišajo vrednot nepremičnin v bližini, vendar je bilo temu raziskovalnemu področju posvečeno le malo empiričnih študii. Zato se v tej študiji preučujejo vplivi celovite sanacije na tržne cene sosednjih nepremičnin na podlagi hedonske analize cen, pri kateri smo uporabili niz panelnih podatkov, ki zajemajo 6.475 nepremičninskih transakcij v Mongkoku, Kowloonu in Hongkongu. To območje smo za preučevanje izbrali zato, ker je bil tam leta 2004 končan obsežen projekt sanacije pod vodstvom URA z imenom Langham Place. Ugotovitve kažejo, da bližina projektne lokacije ni bistveno vplivala na cene stanovanj pred začetkom projekta. Sprememba v razponu cen glede na lokacijo (ang.spatial price gradient) pa je bila vidna po tem, ko se je projekt končal. Izsledki potrjujejo, da cene stanovanj niso odvisne od sprememb v okoljski kakovosti, ki je posledica celovite sanacije, poleg tega pa imajo tudi pomembne praktične posledice za izboljšanje stanovanj in urbano obnovo v Hongkongu.

\section{Teoretični okvir zunanjih učinkov sanacije}

\subsection{Zunanji učinki na nepremičninskem trgu}

Analize vrednosti nepremičnin so se hitro razmahnile po pojavu teorije vedenja odjemalcev (Lancaster, 1966), po kateri je dobrina večdimenzionalni proizvod, ki ga lahko razbijemo v sveženj lastnosti, ki se med seboj razlikujejo po količini in kakovosti. Ta koncept se lahko uporablja za široko paleto dobrin, tudi za stanovanja. Teorijo so dodatno razvili in predlagali, naj bo tržna vrednost hiše skupek tržnih vrednosti različnih lastnosti hiše (Kain in Quigley, 1970). Te lastnosti med drugim zajemajo velikost, komunalno opremljenost, tloris, stanje, dostop in okolico hiše. Ena od značilnih lastnosti stanovanj je nepremičnost. Z drugimi besedami: hišo lahko » potrošimo « samo na kraju, na katerem stoji, in nikjer drugje. $S$ tega vidika lahko kakovost zunanjega okolja nepremičnine pomembno vpliva na vrednost nepremičnine, saj njen lastnik ne more spremeniti zunanje okolice, ki vpliva na gospodarsko vrednost nepremičnine. $\mathrm{Z}$ drugimi besedami, med kakovostjo soseske in vrednostjo nepremičnine obstaja tesna povezava. To ugotovitev so potrdile tudi številne raziskave (na primer Jacobs, 1941; Li in Brown, 1980; Colwell idr., 2000; Boyle in Kiel, 2001, ter Din idr., 2001). V Združenih državah Amerike imajo nepremičnine ob vodi višjo vrednost, in sicer odvisno od vrste in kakovosti razgleda (Benson idr., 1998). Na Novi Zelandiji se lahko vrednost nepremičnine v bližini privlačnih zgradb poveča za $37 \%$ (Bourssa idr., 2004). Nekateri drugi raziskovalci (na primer Michaels in Smith, 1990; Kohlhase, 1991, ter Hamilton in Schwann, 1995) pa so ugotovili, da bližina nezaželene rabe zemljišč, kot sta odlagališče strupenih odpadkov in območje visokonapetostnih vodov, negativno vpliva na vrednost stanovanj.

Spremembe v kakovosti sosesk posledično povzročajo tudi spremembe vrednosti nepremičnin. Značilna primera sprememb v kakovosti soseske sta urbana prenova in gradnja avtocest (Schall, 1971). Ker se projekti urbane prenove običajno osredotočajo na izboljšanje okolja na črnih točkah (Baleiras idr., 2005), lahko močno vplivajo na kakovost sosesk. Preden začne na določenem območju potekati projekt urbane prenove, zapuščene ali slabo vzdrževane stavbe pomenijo ne- 
gativne zunanje učinke (na primer $\mathrm{z}$ vidika neprivlačnosti in nevarnosti za javno zdravje) in tako znižujejo vrednost bližnjih nepremičnin (Clawson, 1975; Wilkinson, 1975; Affuso idr., 2010). Te negativne zunanje učinke lahko odpravimo tako, da zapuščene in propadajoče stavbe $\mathrm{v}$ okolici popravimo, obnovimo in saniramo (Prasad, 1989; Yau in Chan, 2008).

\subsection{Zunanji učinki stanovanjske obnove}

O povečanju vrednosti nepremičnin zaradi stanovanjske obnove je bilo opravljeno že več študij. Različne metodologije so pokazale, da je obnova stanovanj v Hongkongu povzročila višje cene (Chau idr., 2003; Yiu in Leung, 2005; Hui idr., 2008). Prav tako so raziskave potrdile, da je naložba v manjše popravilo lastnikom stanovanj na Novi Zelandiji prinesla od 1- do 8-odstotni dobiček (Fortes in McCarthy, 2010). Vendar so se skoraj vse te raziskave osredotočale na obnovljene nepremičnine in ne na tiste, ki jih niso obnovili. Zunanji učinki obnove stavb so bili do zdaj le slabo raziskani. V neki študiji je bilo celo ugotovljeno, da lastniki stanovanj svojih nepremičnin raje ne vzdržujejo, ker se ne zavedajo pozitivnih zunanjih učinkov, ki bi jih obnova imela za njihove sosede (Pavlov in Blazenko, 2005), vendar je šlo le za analitično raziskavo. V neki drugi raziskavi (Yau idr., 2008) so zato poskušali ugotoviti, ali je obnova povzročila pozitivne zunanje učinke na nepremičnine v bližini. Na podlagi hedonske analize niza panelnih podatkov o nepremičninskih transakcijah v velikem stanovanjskem naselju v predelu Pokfulam v Hongkongu je bilo ugotovljeno, da se je zaradi obnove vrednost nepremičnin nasproti obnovljenih stavb zvišala za 6,6\%, pri čemer se drugi dejavniki niso spremenili.

O vplivih sanacije na vrednost nepremičnin v bližini ni na voljo veliko empiričnih dokazov. V dveh študijah (Chau idr., 2004; Lai idr., 2007) se je preučevalo, kako sta projekta celovite sanacije v hongkonškem predelu Sheung Wan spremenila razpon cen stanovanjskih nepremičnin na območju, na katerem sta potekala. Kljub temu pa ugotovitve študij niso pokazale, da sta projekta vplivala na splošno povečanje cen stanovanj na tem območju. Ker ni empirične raziskave, ki bi potrdila te ugotovitve, ne moremo sklepati, da celovita sanacija ne ustvarja pozitivnih zunanjih učinkov na stanovanja v bližini. Da bi se potrdile ugotovitve predhodnih raziskav, so $v$ tej študiji preučeni zunanji učinki še enega projekta celovite sanacije v Hongkongu.

\section{Metodologija in podatki}

Kot je že bilo omenjeno v poglavju 2.1, je vrednost nepremičnine skupek vrednosti njenih lastnosti (na primer površine, dostopa, tlorisa in kakovosti soseske). Za prikaz vplivov projekta celovite sanacije na vrednosti nepremičnin v soseščini je zelo pomembno, da se pri analizi vse druge lastnosti ali dejavniki ne spreminjajo. $\mathrm{V}$ ta namen se uporablja model hedonske analize cen (ang. hedonic price model, v nadaljevanju: HPM; Court, 1939; Griliches, 1971). Sprva je bila ta tehnika prilagojena določanju vrednosti raznovrstnih dobrin, po izpopolnitvi (Rosen, 1974) pa se je HPM začel uporabljati za vrednotenje uporabnih lastnosti raznovrstnih dobrin. Glede na to, da je stanovanjski trg sestavljen iz implicitnih trgov posameznih lastnosti stanovanj, se lahko HPM uporablja za preučevanje sprememb $\mathrm{v}$ vrednosti stanovanj zaradi sprememb različnih stanovanjskih lastnosti. Rosenovo delo je ponujalo številne nove vpoglede, zato je bilo od takrat precej empiričnih raziskav determinant vrednosti stanovanj opravljenih s pomočjo HPM.

\subsection{Projekt celovite sanacije ulic Argyle in Šanghaj}

Projekt celovite sanacije, na katerega se osredotoča ta študija, poteka na ulicah Argyle in Šanghaj, ki se nahajata na najboljši lokaciji v predelu Mongkok na polotoku Kowloon. Projekt ima dolgo zgodovino. Med pripravo osnutka načrta namenske rabe zemljišč za Mongkok aprila 1988 so predlagali, da bi morala biti projektna lokacija območje celovitega razvoja (ang. Comprehensive Development Area, v nadaljevanju: CDA). Na tem območju je bilo takrat veliko propadajočih stavb, območje pa je bilo označeno kot »rdeča četrt «, saj je bilo tam veliko prostitutk, ki so delale kar v svojih stanovanjih (Emerton, 2001; Liu in Lau, 2006). Mestni načrtovalski odbor je načrt za razvojno območje na ulicah Argyle in Šanghaj odobril

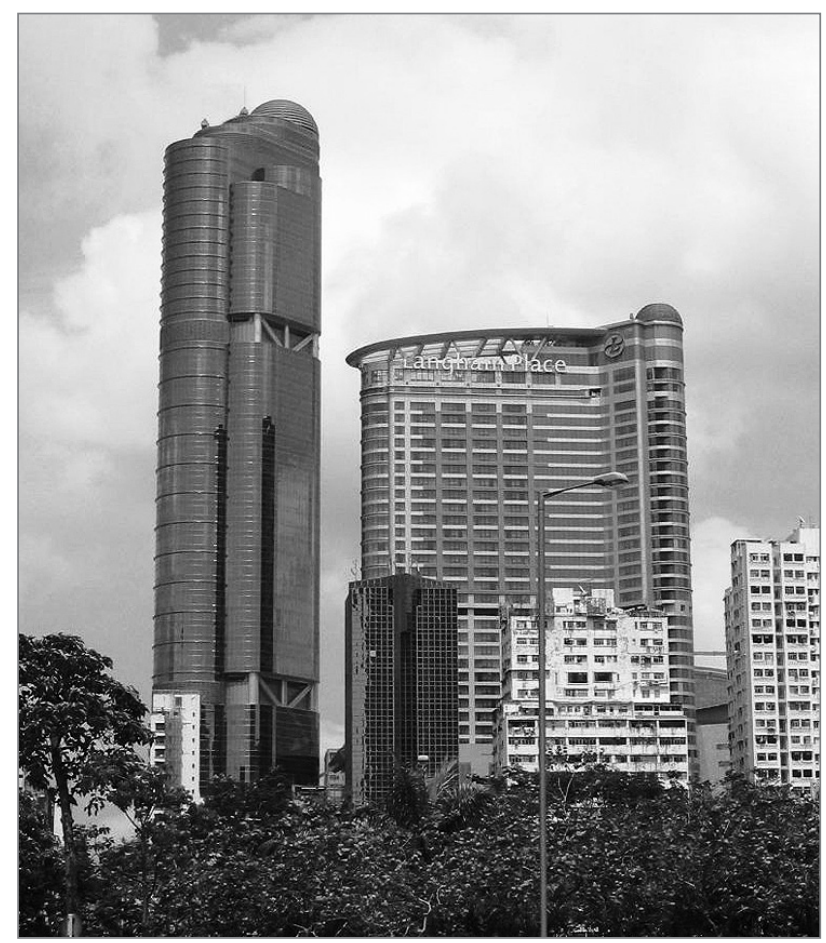

Slika 1: Pogled na kompleks Langham Place z zahodne strani (foto: Yung Yau) 


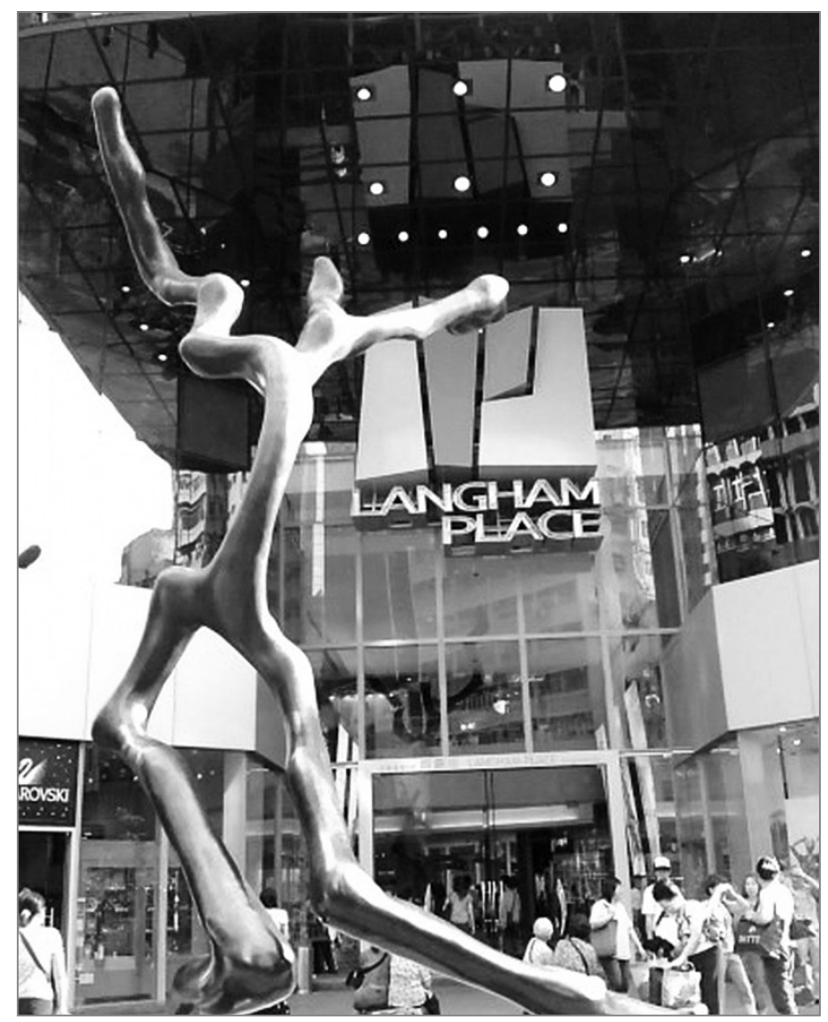

Slika 2: Vhod v nakupovalno središče Langham Place na križišču ulic Argyle in Portland (foto: Yung Yau)

januarja 1991. Prvotno je družba za prostorski razvoj (ang. Land Development Corporation $)^{[1]}$ nameravala projekt končati do leta 1998 , vendar pa ga je zaradi enajstletnega spora glede združevanja zemljišč končno prevzel njen naslednik, URA. Na združeni lokaciji so na koncu v skupnem partnerstvu med podjetjem Great Eagle Holdings Limited in URA zgradili poslovni kompleks z 58-nadstropno poslovno stolpnico, 41-nadstropnim hotelom ( 495 sobami) in s 15-etažnim nakupovalnim središčem na približno $56.000 \mathrm{~m}^{2}$ prodajnih površin. Projekt je bil leta 2003 uradno poimenovan Langham Place, nove prostore pa so odprli konec leta 2004. ${ }^{[2]}$ Leta 2005 je podjetje Great Eagle odkupilo 50-odstotni delež, ki je pripadal URA, in s tem postalo edini lastnik projekta. Sliki 1 in 2 prikazujeta kompleks Langham Place, kot ga lahko vidimo danes, njegova lokacija pa je prikazana na sliki 3 .

Pri projektu Langham Place je šlo za projekt sanacije, ki ga je vodil javni sektor, čeprav je bil izveden prek javno-zasebnega partnerstva. Njegov namen je bil odstraniti nizke propadajoče stavbe in izboljšati splošno podobo ulic. $V$ osnutku načrta namenske rabe zemljišč je bilo CDA določeno za dobro načrtovano stanovanjsko in/ali poslovno rabo z zagotovljenimi odprtimi površinami in drugo podporno infrastrukturo (na primer odprta površina in kulturni dom), saj je bil zagotovljen ustrezen urbanistični nadzor nad različnimi vrstami, obsegom, načrtovanjem in razporeditvijo gradnje. V nasprotju s komasacijo (Yau, 2009) so se morali v tem primeru prvotni stano- valci projektne lokacije izseliti. Tako je bila glavni cilj projekta izboljšava območja. Po končanju projekta se na območjih v bližini pričakujejo pozitivni zunanji učinki (na primer varnejše ulice, lepše stavbe in več javnih dobrin). Zaradi ugodnejšega grajenega okolja bi se morali ti zunanji učinki, ustvarjeni $s$ projektom sanacije, kazati v povečanih vrednostih nepremičnin in višjih cenah najemnin v okolici.

\subsection{Empirični model}

Projekt celovite sanacije vpliva na nepremičnine v bližini, zato smo za ocenjevanje vpliva zunanjih dejavnikov razvili ta HPM:

$\ln R C_{i t}=\alpha_{0}+\alpha_{1}$ STAR $_{i t}+\alpha_{2}$ STAR $_{i t}{ }^{2}+\alpha_{3}$ NADSTR $_{i}+$ $\alpha_{4}$ NADSTR $_{i}^{2}+\alpha_{5}$ POVR $\check{S}_{i}+\alpha_{6}$ POVR $\breve{S}_{i}^{2}+\beta_{1} O D D_{i}+$ $\beta_{2} O D D_{i} \times$ PO_SAN ${ }_{i}+\varepsilon_{i}$,

pri čemer je:

- $R C_{i t}$ realna transakcijska cena nepremičnine $i \mathrm{v}$ času $t$ (merjena v milijonih HKD);

- $S T A R_{i t}$ starost nepremičnine $i$, ki je enaka razliki med datumom izdaje uporabnega dovoljenja in datumom transakcije $t$ (merjena v mesecih);

- NADSTR nadstropje nepremičnine $i$;

- POVRŠ prodajna površina nepremičnine $i$ (merjena $\mathrm{v}$ kvadratnih čevljih);

- $O D D_{i}$ oddaljenost nepremičnine $i$ od središča kompleksa Langham Place oziroma projekta sanacije ulic Argyle in Šanghaj (merjena v metrih);

- PO_SAN, navidezna spremenljivka, ki je enaka 1, če je bila transakcija izvedena po odprtju kompleksa Langham Place, v nasprotnem primeru pa je enaka nič;

- $\alpha_{i}$ koeficient, ki se računa;

- $\beta_{i}$ koeficient, ki se računa; in

- $\varepsilon_{i}$ stohastična spremenljivka.

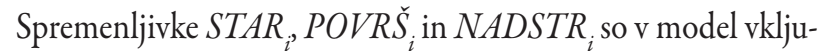
čene zato, da z njimi spremljamo spremembe v cenah zaradi teh konstrukcijskih lastnosti. V modelu so nepogrešljive, saj je bilo ugotovljeno, da te lastnosti pomembno določajo cene nepremičnin, še zlasti v večnadstropnih stanovanjskih stavbah v Hongkongu (na primer Mok, 1995; So idr., 1997; Tse in Love, 2000; Chau idr., 2001, ter Wong idr., 2011). Če te ključne spremenljivke izpustimo, empirični model ne bo pravilno postavljen. Poleg tega so modelu dodane tudi kvadratne vrednosti spremenljivk, s čimer pokrijemo tudi morebitne nelinearne mejne vplive spremenljivk na cene stanovanj. Zaradi sprememb v tržnih razmerah je upoštevana realna cena nepremičnin in ne nominalna. Pri HPM, ki uporabljajo nepremičninske transakcije, ki potekajo v določenem časovnem obdobju, je treba upoštevati tudi morebitne časovne vplive. V ta namen so nominalne cene nepremičnin znižane na podlagi 


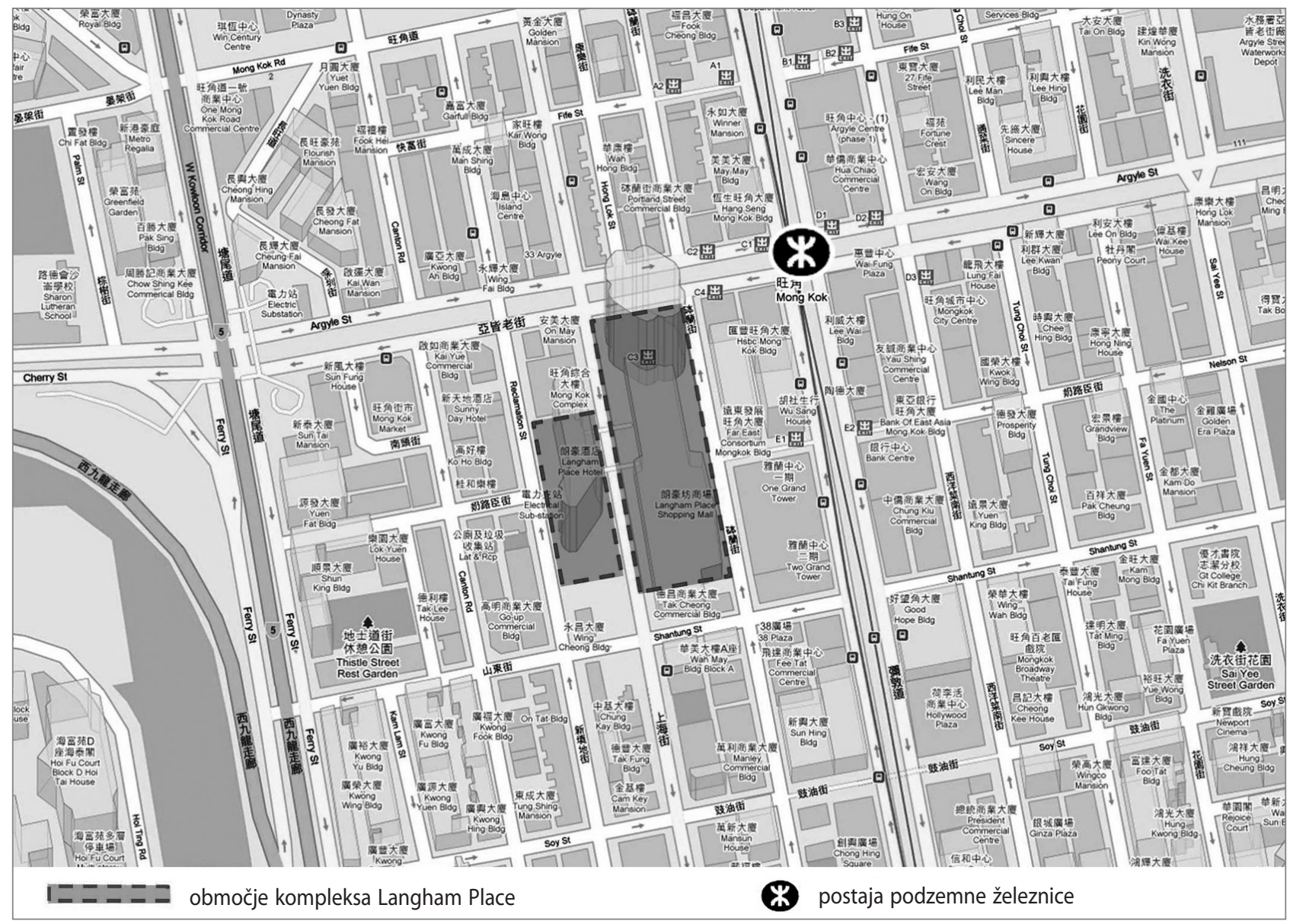

Slika 3: Langham Place (vir: internet 1)

indeksa domačih cen nepremičnin, ki ga oblikuje hongkonški urad za ocenjevanje in vrednotenje. V študiji se osredotočamo na koeficienta $\beta_{1}$ in $\beta_{2}$. Prvi meri razpon cen nepremičnin glede na lokacijo pred odprtjem kompleksa Langham Place, drugi pa razpon cen nepremičnin glede na lokacijo po odprtju kompleksa. Če lahko ob upoštevanju drugih dejavnikov ocenimo, da je koeficient $\beta_{2}$ pomemben, to potrjuje spremembo v razponu cen glede na lokacijo. Transakcijske podatke za stanovanjske nepremičnine v polmeru $500 \mathrm{~m}$ od središča kompleksa Langham Place za obdobje od januarja 2003 do septembra 2006 smo pridobili od raziskovalnega centra za ekonomiko nepremičnin. V tem obdobju je bilo opravljenih skupno 6.475 nepremičninskih transakcij. Statistični podatki so na kratko predstavljeni v preglednici 1. Od teh 6.475 transakcij jih je bilo 2.962 (približno $45,75 \%$ ) opravljenih po odprtju kompleksa Langham Place konec leta 2004.

\section{Ugotovitve in razprava}

\subsection{Ugotovitve}

Rezultati modela hedonske analize cen so prikazani v preglednici 2. Prilagojeni $R$-kvadrat znaša 0,86 , kar je za hedonsko analizo cen razmeroma visoko. Vsi izračunani koeficienti kon- strukcijskih lastnosti so statistično pomembni vsaj na 10-odstotni ravni. Rezultati kažejo, da je cena nepremičnin $s$ starostjo upočasnjeno padala ter upočasnjeno naraščala glede na površino in nadstropje stanovanja. Te ugotovitve se ujemajo s pričakovanji in z ugotovitvami prejšnjih raziskav. Koeficient navidezne spremenljivke $O D D$ (to je $\beta_{1}$ ) je bil negativen in statistično pomemben na 5-odstotni ravni. To pomeni, da so se nepremičnine, ki so bile bližje območju sanacije, pred odprtjem kompleksa Langham Place (konec leta 2004) prodajale po višji ceni, če upoštevamo, da se vsi drugi dejavniki niso spremenili. Vendar pa je hedonska analiza cen pokazala statistično nepomemben koeficient za vzajemno spremenljivko ODD*PO_SAN (to je $\beta_{2}$ ), kar pomeni, da projekt sanacije ulic Argyle in Šanghaj ni vplival na spremembo razpona cen stanovanjskih nepremičnin $\mathrm{v}$ bližini glede na lokacijo.

\subsection{Pomen izsledkov}

Zdi se, da pozitivni koeficient $\beta_{1}$ izpodbija prvotno domnevo, da bližina propadajočega območja povzroča nižjo vrednost stanovanj zaradi negativnih zunanjih učinkov, čeprav lahko na sliki 3 vidimo, da je projekt potekal v središču Mongkoka in $\mathrm{v}$ bližini postaje podzemne železnice. Mogoče pa je negativne 
Preglednica 1: Opisni statistični podatki o nepremičninskih transakcijah

\begin{tabular}{lllll}
\hline Lastnost & Povprečje & $\sigma$ & Min. & Maks. \\
\hline realna cena nepremičnine (v milijonih HKD) & 2,18 & 2,040 & 0,02 & 12,11 \\
\hline površina (v kv. čevljih) & 358,57 & 115,74 & 158,49 & $1.006,81$ \\
\hline nadstropje & 13,79 & 11,04 & 1,00 & 51,00 \\
\hline starost (v mesecih) & 238,67 & 168,53 & 0,00 & 589,00 \\
\hline oddaljenost od projekta sanacije ulic Argyle in Šanghaj (v metrih) & 237,12 & 98,41 & 35,00 & 500,00 \\
\hline
\end{tabular}

zunanje učinke izničila višja stopnja primernosti in dostopa zaradi bližine projektne lokacije. Kljub temu izsledki te raziskave še vedno potrjujejo predhodne ugotovitve (Chau idr., 2004; Lai idr., 2007), da v Hongkongu projekti celovite sanacije v splošnem niso zvišali cen stanovanjskih nepremičnin v soseskah, če upoštevamo, da so vsi drugi dejavniki ostali enaki. Ugotovitve tako kažejo, da preučevani projekt celovite sanacije ni ustvaril splošnega pozitivnega zunanjega učinka. Mogoč vzrok za v splošnem nepomembne pozitivne zunanje učinke, ki se je pokazal pri empirični analizi, so negativni okoljski vplivi (na primer manj odprtih površin ter ovirana naravna svetloba in prezračevanje), ki jih je ustvaril orjaški kompleks Langham Place. Občani in lokalne okoljevarstvene skupine so se pritoževali, da je Langham Place ustvaril pregrado, ki ovira pretok zraka na območju (Nichol, 2008). Predel Mongkok je izredno prometen, veter pa ima pomembno vlogo pri razkajanju izpušnih plinov motornih vozil. Ko se je zaradi kompleksa zaprl ali zavrl pretok vetrov, se je za lokalne prebivalce, še zlasti tiste, ki živijo blizu projekta sanacije, kakovost zraka močno poslabšala. Vse to se izraža na stanovanjskem trgu in izničuje koristi, ki jih je projekt prinesel (na primer odstranitev propadajočih stavb).
Empirične ugotovitve te študije lahko prav tako izpodbijajo tradicionalno razmišljanje o razmerju med gentrifikacijo in urbano prenovo. Prizadevanja, povezana z urbano prenovo, so bila pogosta tarča kritik, saj so običajno uničila več nizkocenovnih stanovanj v soseski, kot so jih ustvarila, zaradi česar so se morali revni prebivalci preseliti, si drugje poiskati stanovanje nižje kakovosti ali pa so postali brezdomci (Pozdena, 1988). V mnogih raziskavah je ugotovljena tesna povezava med urbano prenovo in gentrifikacijo (na primer Munro, 1993; Wagner, 1995, in Wilson, 1996). Raziskava gentrifikacije v različnih večjih mestih v ZDA je pokazala, da je sanacija v večini primerov pripeljala do gentrifikacije (Wilson, 1996). Gentrifikacijske vplive urbane prenove lahko pojasnimo s pomočjo teorije »vrzeli v najemnini« (ang. rent gap theory; Smith, 1979), po kateri gentrifikacijo povzročijo investitorji ali lastniki, ki služijo na račun sprememb rabe zemljišč v mestnih soseskah. Vrzel v najemnini je torej »razlika med potencialno ravnijo najemnine za zemljišče in dejansko najemnino, ki se glede na trenutno rabo zemljišča obračunava po višji ceni« (Smith, 1979: 545). Tovrstno razmišljanje o gentrifikaciji je podprto tudi z nekaterimi empiričnimi študijami (na primer Clark, 1987), $\mathrm{v}$ okviru katerih se je pokazalo, da imajo vrzeli v najemnini

Preglednica 2: Rezultati modela regresijske hedonske analize cen

\begin{tabular}{|c|c|c|c|c|c|}
\hline \multicolumn{6}{|c|}{ Odvisna spremenljivka: In RC } \\
\hline \multirow{2}{*}{$\begin{array}{l}\text { neodvisna spremenljivka } \\
\text { KONSTANTA }\end{array}$} & \multirow{2}{*}{$\begin{array}{l}\text { koeficient } \\
-0,411107\end{array}$} & \multirow{2}{*}{$\begin{array}{l}\text { standardna napaka } \\
0,028999\end{array}$} & \multirow{2}{*}{$\begin{array}{r}\text { t-statistika } \\
-14,17652\end{array}$} & \multicolumn{2}{|c|}{$p$-vrednost } \\
\hline & & & & 0,0000 & $* * *$ \\
\hline STAR & $-0,003759$ & 0,000101 & $-37,39666$ & 0,0000 & $* * *$ \\
\hline STAR & $2,87 \times 10^{-6}$ & $1,93 \times 10^{-7}$ & 14,86835 & 0,0000 & $* * *$ \\
\hline NADSTR & 0,010424 & 0,001112 & 9,373329 & 0,0000 & $* * *$ \\
\hline$N^{\prime} A D S T R^{2}$ & $-4,40 \times 10^{-5}$ & $2,47 \times 10^{-5}$ & $-1,783935$ & 0,0745 & * \\
\hline POVRŠ & 0,003870 & $8,21 \times 10^{-5}$ & 47,14263 & 0,0000 & $* * *$ \\
\hline POVRŠ́ ${ }^{2}$ & $-1,51 \times 10^{-6}$ & $6,59 \times 10^{-8}$ & $-22,90464$ & 0,0000 & $* * *$ \\
\hline$O D D$ & $-8,36 \times 10^{-5}$ & $4,23 \times 10^{-5}$ & $-1,975285$ & 0,0483 & $* *$ \\
\hline ODD*PO_SAN & $2,29 \times 10^{-5}$ & $2,86 \times 10^{-5}$ & 0,799986 & 0,4237 & \\
\hline prilagojen $R$-kvadrat & 0,857634 & Durbin-Watsonova st & & 1,002656 & \\
\hline F-statistika & 4876,035 & Akaikov informacijsk & & 0,366094 & \\
\hline verjetnost (F-statistika) & 0,000000 & število opazovanj & & 6.475 & \\
\hline
\end{tabular}

Opomba: oznake $\left({ }^{* *}\right),\left({ }^{* *}\right)$ in $\left({ }^{*}\right)$ pomenijo, da so izračunani koeficienti spremenljivk statistično pomembni na $1-\left({ }^{* * *}\right)$, 5- $\left({ }^{* *}\right)$ in 10 -odstotni ravni $\left.{ }^{*}\right)$. Vsi koeficienti so bili izračunani s pomočjo Whiteovih heteroskedastično skladnih standardnih napak. 
pomembno vlogo pri pospeševanju gentrifikacije $\mathrm{v}$ švedskem mestu Malmö.

Kljub temu ugotovitve te študije kažejo, da se razpon cen glede na lokacijo za nepremičnine v bližini projekta sanacije ulic Argyle in Šanghaj v Hongkongu po končanju projekta ni spremenil. Te ugotovitve očitno tudi ne podpirajo teorije vrzeli v najemnini. Da pa bi to teorijo lahko ovrgli, je potrebnih še več raziskav, $s$ katerimi bi se preučilo, ali projekti celovite sanacije vplivajo na splošno povečanje vrednosti nepremičnin v bližini. Ko enačbi dodamo navidezno spremenljivko PO_SAN in HPM uporabimo na enakem nizu panelnih podatkov, izračunani koeficient te dodatne navidezne spremenljivke ni statistično pomemben na 10-odstotni ravni, čeprav je pozitiven. Ti rezultati potrjujejo, da do gentrifikacije ni prišlo zaradi projekta sanacije ulic Argyle in Šanghaj in da pojava gentrifikacije ne moremo pojasniti s pomočjo teorije vrzeli v najemnini.

\section{Sklep}

Celovita sanacija, ki je ena izmed oblik urbane obnove ter katere cilj je odpraviti prvine, ki kazijo mestno podobo, in izboljšati grajeno okolje, naj bi ustvarjala pozitivne zunanje učinke na nepremičnine v bližini. Da bi to hipotezo preverili, smo na nizu podatkov o transakcijah stanovanjskih nepremičnin $\mathrm{v}$ bližini projekta sanacije ulic Argyle in Šanghaj v Hongkongu opravili hedonsko analizo cen. Ugotovitve kažejo, da se razpon cen glede na lokacijo za nepremičnine v bližini po tem, ko se je projekt končal, ni spremenil, kar potrjuje ugotovitve prejšnjih študij (na primer Chau idr., 2004, ter Lai idr., 2007). Očitno projekti celovite sanacije, ki so jih sprožili javni organi, niso bili dovolj učinkoviti, da bi izboljšali območja v okolici projektov. Kakor koli že, na trgu zasebnih stanovanj ni vidne splošne koristi. URA in hongkonška vlada bi morali spremeniti način izvajanja pobud urbane prenove, tako da bi od njih imele koristi tudi lokalne skupnosti, saj drugače poraba javnega denarja za financiranje teh projektov ni upravičena. Poleg tega študija vzbuja dvom o uporabnosti teorije vrzeli v najemnini za razlago gentrifikacije, ki naj bi jo povzročila prenova. Potrebne so nadaljnje raziskave, $s$ katerimi bi se pokazalo, ali je na območju kompleksa Langham Place sploh prišlo do gentrifikacije.

Študija je nekakšen uvod v preučevanje zunanjih učinkov prenove stanovanj v Hongkongu, pri čemer pa se osredotoča le na obsežen javni projekt sanacije v starem predelu Hongkonga. Uporabno bi bilo preučiti vplive različnih vrst projektov urbane prenove in sanacije na stanovanjski trg. $Z$ nadaljnjimi raziskavami bi lahko na primer ugotavljali, ali projekti sanacije, ki jih sproži zasebni sektor, ustvarjajo splošne pozitivne zunanje učinke na vrednost bližnjih nepremičnin. Poleg tega je lahko pomemben tudi obseg gradnje ali prenove. Rušenje propadajoče zgradbe in gradnja nove zgradbe, podobne veli- kosti, na isti lokaciji imata lahko več pozitivnih kot negativnih zunanjih učinkov na nepremičnine v bližini. Poleg tega lahko primerjamo tudi učinke, ki jih imajo projekti sanacije in prenove stanovanj na sosesko. Vse te predlagane raziskave lahko dajo javnim upravljavcem in urbanistom dragocene vpoglede $\mathrm{v}$ to, kako bi morala urbana prenova potekati, da bi se dosegla bolj upravičena gospodarska in okoljska trajnost.

\section{Yung Yau}

City University of Hong Kong, Department of Public and Social

Administration, Kowloon Tong, Hongkong

E-pošta:y.yau@cityu.edu.hk

\section{Opombe}

[1] Družba za prostorski razvoj je bila gospodarska družba, ki se je ukvarjala predvsem z urbano prenovo v Hongkongu. Ob ustanovitvi leta $1987 \mathrm{ji}$ je vlada ponudila obrestno neobnavljajoče se posojilo, da bi podprla njeno poslovanje (urad za prostorski razvoj, 2000). Leta 2001 jo je zamenjal URA.

[2] Slovesna otvoritev lokacije Langham Place je potekala 4. marca 2005.

\section{Zahvala}

Delo, opisano $v$ tem članku, je bilo financirano s pomočjo štipendije sveta za raziskovalne štipendije posebnega upravnega območja Ljudske republike Kitajske Hongkong (projekt št. CityU 1508/08). Prvotna različica članka je bila predstavljena na konferenci z naslovom European Real Estate Society Conference, ki je potekala v Stockholmu leta 2009. Avtor se zahvaljuje udeležencem konference za dragocene komentarje in predloge, ki so mu pomagali pri pisanju tega članka. Poleg tega bi se rad zahvalil tudi Phoebe Chau in Joeju Chuju za njuno pomoč pri zbiranju in združevanju podatkov.

\section{Viri in literatura}

Affuso, E., de Parisot, C. V., Ho, C., in Hite, D. (2010): Vpliv nevarnih odpadkov na vrednost nepremičnin: posledice onesnaženja s svincem [The impact of hazardous waste on property values: The effect of lead pollution]. Urbani izziv, 21(2), str. 48-57 [117-126]. DOI: urbani-izziv-2010-21-02-005

Andersen, H. S. (1995): Explanations of decay and renewal in the housing market: What can Europe learn from American research? Journal of Housing and the Built Environment, 10(1), str. 65-85. DOI: 10.1007/ BF02498059

Baleiras, R. N., Monteiro, R. S., in Reis, A. B. (2005): Tax dividend evaluation of major urban renewal projects. Prispevek je bil predstavljen na konferenci z naslovom EcoMod2005 International Conference on Policy Modeling, ki je potekala od 29. junija do 1. julija 2005 v Istanbulu v Turčiji.

Benson, E. D., Hansen, J. L., Schwartz, A. L., Jr., in Smersh, G. T. (1998): Pricing residential amenities: The value of a view. Journal of Real Estate Finance and Economics, 16(1), str. 55-73. DOI: 10.1023/A:1007785315925

Bourassa, S. C., Hoesli, M., in Sun, J. (2004): What's in a view? Environment and Planning A, 36(8), str. 1427-1450. DOI: 10.1068/a36103 
Boyle, M. A., in Kiel, K. A. (2001): A survey of house price hedonic studies of the impact of environmental externalities. Journal of Real Estate Literature, 9(2), str. 117-144.

Broadway, R. W. (1974): The welfare foundations of cost-benefit analysis. The Economic Journal, 84(336), str. 926-939. DOI: 10.2307/2230574

Chau, K. W., Lai, L. W. C., Wong, W. S., Yiu, C. Y., in Wong, S. K. (2004): The economic and social impact of redevelopment - A Hong Kong case study. V: Leung, A. Y. T., in Yiu, C. Y. (ur.): Building dilapidation and rejuvenation in Hong Kong, str. 58-66. Hongkong, The Hong Kong Institute of Surveyors and City University of Hong Kong.

Chau, K. W., Leung, A. Y. T., Yiu, C. Y., in Wong, S. K. (2003): Estimating the value enhancement effects of refurbishment. Facilities, 21(1/2), str. 13-19. DOI: 10.1108/02632770310460504

Chau, K. W., Ma, S. M., in Ho, D. C. W. (2001): The pricing of luckiness in the apartment market. Journal of Real Estate Literature, 9(1), str. 31-40.

Clark, E. (1987): The rent gap and urban change: Case studies in Malmö 1860-1985. Lund, Lund University Press.

Clawson, M. (1975): Economic and social conflicts in land use planning Natural Resources Journal, 15(3), str. 473-490.

Colwell, P. F., Dehring, C. A., in Lash, N. A. (2000): The effect of group homes on neighbourhood property value. Land Economics, 76(4), str. 615-637. DOI: 10.2307/3146956

Court, A. T. (1939): Hedonic price index with automotive examples. V: General Motors Corporation (ur.): The dynamics of automobile demand, str. 98-119. New York.

De Kleijn, G. (1986): The state of urban renewal. Journal of Housing and the Built Environment, 1(3), str. 235-251.

Din, A., Hoesli, M., in Bender, A. (2001): Environmental variables and real estate prices. Urban Studies, 38(11), str. 1989-2000. DOI: 10.1080/00420980120080899

Dumouchel, J. R. (1975): Dictionary of development terminology. New York, McGraw-Hill.

Družba za prostorski razvoj (2000): The LDC experience: 12 years' efforts of urban renewal. Hongkong.

Emerton, R. (2001): Trafficking of women into Hong Kong for the purpose of prostitution: Preliminary research findings. Priložnostni prispevek št. 3. Hongkong, Centre for Comparative and Public Law, Faculty of Law, University of Hong Kong.

Fortes, R., in McCarthy, I. (2010): Renovate for profit: New Zealand residential case study. Property Management, 28(5), str. 358-369. DOI: 10.1108/02637471011086545

Griliches, Z. (ur.) (1971): Price indexes and quality change. Cambridge, MA, Harvard University Press.

Hamilton, S. W., in Schwann, G. M. (1995): Do high voltage electric transmission lines affect property value? Land Economics, 71(4), str. 436-444. DOI: 10.2307/3146709

Hui, E. C. M., Wong, J. T. Y., in Wan, J. K. M. (2008): The evidence of value enhancement resulting from rehabilitation. Facilities, 26(1/2), str. 16-32. DOI: $10.1108 / 02632770810840282$

Internet 1: http://www.ypMap.com (sneto 10. 7. 2011).

Jacobs, J. L. (1941): Neighbourhood and property obsolescence in the assessment process. The Journal of Land and Public Utility Economics, 17(3), str. 344-352. DOI: 10.2307/3158370

Kain, J. F., in Quigley, J. M. (1970): Measuring the value of housing quality. Journal of the American Statistical Association, 65(330), str. 532-548. DOI: $10.2307 / 2284565$
Khaki, A., Somma, P., in Thomas, H. (1999): Urban renewal, ethnicity and social exclusion in Europe. Aldershot, Ashgate.

Kohlhase, J. E. (1991): The impact of toxic waste sites on housing values. Journal of Urban Economics, 30(1), str. 1-26. DOI: 10.1016/0094-119 0(91)90042-6

Lai, L. W. C., Chau, K. W., Yiu, E. C. Y., Wong, K. S. K., Wong, W. S., in Chan, P. Y. L. (2007): Measuring and interpreting the effects of a public-sector-led urban renewal project on housing prices - An empirical study of a comprehensive development area zone developed upon taking in Hong Kong. Environment and Planning B, 34(3), str. 524-538. DOI: $10.1068 / \mathrm{b} 31139$

Lancaster, K. J. (1966): A new approach to consumer theory. Journal of Political Economy, 74(2), str. 132-157. DOI: 10.1086/259131

Li, M. M., in Brown, J. (1980): Micro-neighbourhood externalities and hedonic housing price. Land Economics, 56(2), str. 125-141. DOI: $10.2307 / 3145857$

Lichfield, N. (1966): Cost benefit analysis in urban development - A case study: Swanley. Papers in Regional Science, 16(1), str. 129-153. DOI: 10.1007/BF01888943

Lichfield, N. (1967): The evaluation of capital investment projects in town centre redevelopment. Public Administration, 45(2), str. 129-148. DOI: 10.1111/j.1467-9299.1967.tb02033.x

Liu, G., in Lau, J. (2006): Sexuality as public spectacle: The transformation of sex information and service in the age of the internet. V: Law, P. L., Fortunati, L., in Yang, S. (ur.): New technology in global societies, str. 259-288. Singapur, World Scientific. DOI: $10.1142 / 9789812773555-0012$

Messner, S. D. (1967): A benefit-cost analysis of urban redevelopment: A case study of the Indianapolis program. Bloomington, Bureau of Business Research, Indiana University.

Michaels, R. G., in Smith, V. K. (1990): Market segmentation and valuing amenities with hedonic models: The case of hazardous waste sites. Journal of Urban Economics, 28(2), str. 223-242. DOI: 10.1016/00941190(90)90052-0

Mok, H. M. K. (1995): A hedonic approach to pricing of residential properties in Hong Kong. Hong Kong Journal of Business Management, 13(1), str. 1-15.

Munro, M. (1993): Evaluating the links between housing change and economic change. Urban Studies, 30(2), str. 387-398. DOI: 10.1080/00420989320080361

Nichol, J. (2008) "Upper limit" of heat islands still way too high. South China Morning Post, 6. 6. 2008, str. 14.

Pavlov, A., in Blazenko, G. W. (2005): The neighbourhood effect of real estate maintenance. The Journal of Real Estate Finance and Economics, 30(4), str. 327-340. DOI: 10.1007/s11146-005-7011-9

Pozdena, R. J. (1988): The modern economics of housing: A guide to theory and policy for finance and real estate professionals. New York, Quorum Books.

Prasad, D. R. (ur.) (1989): Urban renewal: The Indian experience. New Delhi, Sterling.

Rosen, S. (1974): Hedonic prices and implicit markets: Product differentiation in pure competition. The Journal of Political Economy. 82(1), str. 34-55. DOI: 10.1086/260169

Rosenthal, S. S., in Helsley, R. W. (1994): Redevelopment and the urban land price gradient. Journal of Urban Economics, 35(2), str. 182-200. DOI: 10.1006/juec.1994.1012 
Rothenberg, J. (1967): Economic evaluation of urban renewal: Conceptual foundation of benefit-cost analysis. Washington, DC, Brookings Institution.

Schall, L. D. (1971): A note on externalities and property valuation. Journal of Regional Science, 11(1), str. 101-105. DOI: 10.1111/ j.1467-9787.1971.tb00244.x

Smith, N. (1979): Toward a theory of gentrification: A back to the city movement by capital not people. Journal of the American Planning Association, 45(4), str. 538-548. DOI: 10.1080/01944367908977002

So, H. M., Tse, R. Y. C., in Ganesan, S. (1997): Estimating the influence of transport on house prices: Evidence from Hong Kong. Journal of Property Valuation and Investment, 15(1), str. 40-47. DOI: 10.1108/14635789710163793

Tse, R. Y. C., in Love, P. E. D. (2000): Measuring residential property values in Hong Kong. Property Management, 18(5), str. 366-374. DOI: $10.1108 / 02637470010360669$

Urad za stanovanja, načrtovanje in zemljišča (2005): Public consultation on mandatory building inspection. Hongkong.

Wagner, G. (1995): Gentrification, reinvestment and displacement in Baltimore. Journal of Urban Affairs, 17(1), str. 81-96. DOI: 10.1111/ j.1467-9906.1995.tb00523.x

Wilkinson, R. K. (1975): Economic aspects of low income housing policy in the urban economy. International Journal of Social Economics, 2(2), str. 73-86. DOI: 10.1108/eb013778

Wilson, F. H. (1996): Urban redevelopment and the post-industrial city: The persistence of gentrification in central cities, 1980-1990. V: Peck, D. L., in Hollingsworth, J. S. (ur.): Demographic and Structural Changes: The Effects of the 1980s on America Society, str. 142-168. Westport, CT, Greenwood Press.

Wong, S. K., Chau, K. W., Yau, Y., in Cheung, A. K. C. (2011): Property price gradients: The vertical dimension. Journal of Housing and Built Environment, 26(1), str. 33-45. DOI: 10.1007/s10901-010-9203-8

Yau, Y. (2009): Raziskava o sprejemljivosti komasacije za urbano prenovo $v$ Hongkongu [A study on the acceptability of land readjustment for urban regeneration in Hong Kong]. Urbani izziv, 20(2), str. 36-44 [105-114]. DOI: 10.5379/urbani-izziv-2009-20-02-004

Yau, Y., in Chan, H. L. (2008): To rehabilitate or redevelop? A study of the decision criteria for urban regeneration projects. Journal of Place Management and Development, 1(3), str. 272-291. DOI: $10.1108 / 17538330810911262$

Yau, Y., Chau, K. W., Ho, D. C. W., in Wong, S. K. (2008): An empirical study on the positive externality of building refurbishment. International Journal of Housing Markets and Analysis, 1(1), str. 19-32. DOI: $10.1108 / 17538270810861139$

Yiu, C. Y., in Leung, A. Y. T. (2005): A cost-and-benefit evaluation of housing rehabilitation. Structural Survey, 23(2), str. 138-151. DOI: 10.1108/02630800510593701 